\title{
GENETIC ALGORITHM BASED CONGESTION MANAGEMENT BY USING OPTIMUM POWER FLOW TECHNIQUE TO INCORPORATE FACTS DEVICES IN DEREGULATED ENVIRONMENT
}

\author{
S.Vinod Kumar' ${ }^{1}$ J.Sreenivasulu' ${ }^{2}$, K.Vimala Kumar ${ }^{3}$ \\ PG Student, Department of EEE, JNTUACEP, Kadapa, A.P, India ${ }^{1}$ \\ Assistant Professor, Department of EEE, JNTUACEP, Kadapa, A.P, India ${ }^{2}$ \\ Assistant Professor, Department of EEE, JNTUACEP, Kadapa, A.P, India ${ }^{3}$
}

\begin{abstract}
Congestion management is one of the important techniques to relieve congestion in transmission system. The usage of transmission line crosses the limits, then congestion occurs. Application of FACTS controllers is as a solution to the problem of congestion management. In the literature Genetic Algorithm (GA) based Optimum Power Flow (OPF) technique is used to determine the optimal location of Static VAR Compensator (SVC). But in this paper Unified-Power-Flow Controller (UPFC) is modeled and located in the system to relieve congestion, also compared with the SVC. This method was applied on IEEE 30-bus test system and a program was developed in MATLAB software environment.
\end{abstract}

Keywords: Flexible Alternative Current Transmission System (FACTS), Congestion Management, Optimum Power Flow (OPF), Genetic Algorithm (GA), Static VAR Compensator (SVC), Unified-Power-Flow Controller (UPFC).

\section{INTRODUCTION}

When the generation and consumption of electric power causes the transmission system to operate beyond transfer limits, the system is said to be under congestion. Congestion management is the process to avoid or relieve the congestion. In a broader sense, congestion management is considered as a systematic approach for scheduling and matching generation and loads in order to reduce congestion [1], [2].

A bilateral transaction is made by a GENCO-DISCO pair without third party intervention while a multilateral transaction is a purchases and sales agreement between several GENCOs and DISCOs possibly supplemented by third parties, such as brokers or forward contractors[3],[4]. What is common between bilateral and multilateral transactions is that the quantities traded and prices agreed upon are up to market participants to decide and not a matter for the ISO. The IS0 only provides power transport facilities. To relieve the congestion ISO can use mainly two types of techniques which are as follows [5]:

\section{A. Cost-free methods:}

i). Out-aging of congested lines.

ii). Operation of transformer taps/phase shifters.

iii). Operation of FACTs devices.

\section{B. Non-cost-free methods:}

Re-dispatch of generation in a manner different from the natural settling point of the market. Some generators back down while others increase their output. The effect of this is that generators no longer operate at equal incremental costs.Curtailment of loads and the exercise of load interruption options.

Among the above two main techniques cost-free methods have advantages like it is not going to touch economic matters so that to relieve the congestion GENCOs and DISCOs will not come into picture. In this paper FACTS devices are used to relieve the congestion because they possess many advantages as compared with the other techniques.

In congestion management the objective function and constraints are nonlinear and non-convex. To solve such equations classical techniques offer good results but when the search space is nonlinear and has discontinues these techniques become difficult to solve with a slow convergence ratio not always seeking to the optimal solution. New numerical methods are then needed to cope with these difficulties especially those with high-speed search to the optimal and not being trapped in local minima. Recently a great deal of interest in promising genetic algorithm and its application to various disciplines including power system planning operation and control. Genetic algorithms are also being applied to a wide range of optimization and learning problems in many domains. Genetic algorithms lend themselves well to power system 
optimization, and can offer significant advantages in a solution methodology and optimization performance. The objective of this paper is to develop a GA based OPF to relieve congestion by optimal locating FACTS devices in a transmission line [5], [6]. In this paper section II discuss about static modelling of SVC and UPFC. Section III describes about problem formulation and Optimum Power Flow (OPF). In Section IV, describes about Genetic Algorithm. In section $\mathrm{V}$, results and discussions are presented. In section VI, optimum location of SVC and UPFC discussed and finally in section VII, conclusions are given.

\section{MODELING OF SVC \& UPFC}

\subsection{Modelling of SVC}

The SVC can be operated as both inductive and capacitive compensation. It is modelled as an ideal reactive power injection at bus $\mathrm{i}$.

$$
\Delta \mathrm{Q}_{i s}=\Delta \mathrm{Q}_{s v c}
$$

The primary purpose of SVC is usually to control voltages at weak points in a network. This may be installed at midpoint of the transmission line. The reactive power output of the SVC can be expressed as follows [5].

$$
\mathrm{Qsvc}=\frac{\mathrm{v}_{\mathrm{i}}\left(\mathrm{v}_{\mathrm{i}}-\mathrm{v}_{\mathrm{r}}\right)}{\mathrm{X}_{\mathrm{sl}}}
$$

Where $\mathrm{X}_{s l}$ is the equivalent slope reactance in p.u. and $\mathrm{v}_{r}$ are reference voltage magnitude. The model of SVC is a shunt connected static VAR generator or absorber with susceptance value $B_{\text {svc }}$ as shown in Fig. 1 .

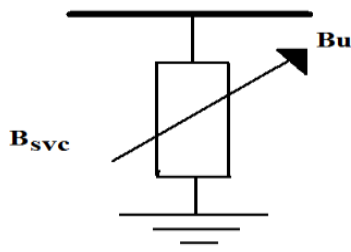

Fig.1. SVC Structure

\subsection{Modelling of UPFC}

Basically, the UPFC has two voltage source inverters (VSI) sharing a common dc storage capacitor. It is connected to the system through two coupling transformers. The schematic representation of the UPFC is shown in Fig. 2. It consists of two voltage source converters and a dc circuit represented by the capacitor. Converter 1 is primarily used to provide the real power demand of converter 2 at the common dc link terminal from the ac power system. Converter 1 can also generate or absorb reactive power at its ac terminal, which is independent of the active power transfer to (or from) the dc terminal.

Converter 2 is used to generate a voltage source at the fundamental frequency with variable amplitude $\left(0 \leq \mathrm{V}_{\mathrm{T}} \leq \mathrm{V}_{\mathrm{TMAX}}\right)$ and phase angle $\left(0 \leq \emptyset_{\mathrm{T}} \leq 2 \pi\right)$, which is

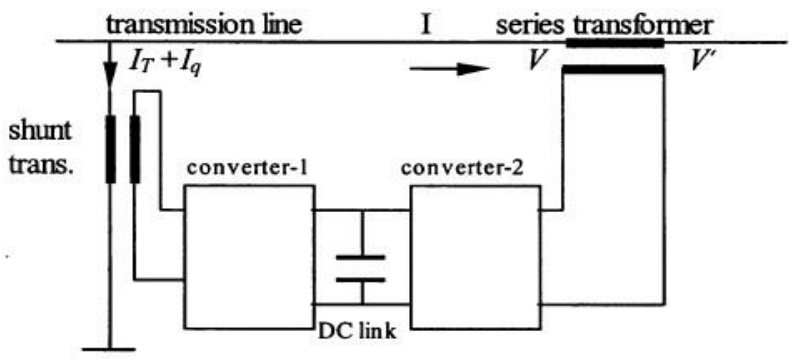

Fig.2. The UPFC basic Circuit Arrangement

added to the ac transmission line by the series-connected boosting transformer.The inverter output voltage injected in series with line can be used for direct voltage control, series compensation, phase shifter, and their combinations. The placement of UPFC in a transmission line between node $\mathrm{i}$ and node $\mathrm{j}$ is as shown in fig. 3 .

$\mathrm{P}_{\mathrm{is}}=\mathrm{V}_{\mathrm{T}}{ }^{2} \mathrm{~g}_{\mathrm{ij}}-2 \mathrm{~V}_{\mathrm{i}} \mathrm{V}_{\mathrm{T}} \mathrm{g}_{\mathrm{ij}} \cos \left(\emptyset_{\mathrm{T}}-\delta_{\mathrm{i}}\right)+\mathrm{V}_{\mathrm{j}} \mathrm{V}_{\mathrm{T}}\left[\mathrm{g}_{\mathrm{ij}} \cos \left(\emptyset_{\mathrm{T}}-\delta_{\mathrm{i}}\right)+\right.$ bijsin $\emptyset \mathrm{T}-\delta \mathrm{i}]$

$\mathrm{P}_{\mathrm{js}}=\mathrm{V}_{\mathrm{j}} \mathrm{V}_{\mathrm{T}}\left[\mathrm{g}_{\mathrm{ij}} \cos \left(\emptyset_{\mathrm{T}}-\delta_{\mathrm{i}}\right)-\mathrm{b}_{\mathrm{ij}} \sin \left(\emptyset_{\mathrm{T}}-\delta_{\mathrm{i}}\right)\right]$

$\mathrm{Q}_{\mathrm{is}}=\mathrm{V}_{\mathrm{i}} \mathrm{I}_{\mathrm{q}}+\mathrm{V}_{\mathrm{i}} \mathrm{V}_{\mathrm{T}}\left[\mathrm{g}_{\mathrm{ij}} \sin \left(\emptyset_{\mathrm{T}}-\delta_{\mathrm{i}}\right)+\left(\mathrm{b}_{\mathrm{ij}}+\frac{\mathrm{B}}{2}\right) \cos \left(\emptyset_{\mathrm{T}}-\delta_{\mathrm{i}}\right)\right]$

$Q_{j s}=-V_{j} V_{T}\left[g_{i j} \sin \left(\emptyset_{T}-\delta_{i}\right)+b_{i j} \cos \left(\emptyset_{T}-\delta_{i}\right)\right] \ldots(6)$

Where,

$\mathrm{V}_{T} \quad=$ The magnitude and the angle of inserted voltage.

$\emptyset_{T} \quad=$ The angle of inserted voltage.

$\mathrm{I}_{Q} \quad=$ The magnitude of the current.

$\mathrm{P}_{\text {is }} \quad=$ The injected active power at bus-i.

$\mathrm{P}_{\mathrm{js}} \quad=$ The injected active power at bus-j.

$\mathrm{Q}_{\mathrm{is}} \quad=$ The injected reactive power at bus-i.

$\mathrm{Q}_{\mathrm{js}} \quad=$ The injected reactive power at bus-j.

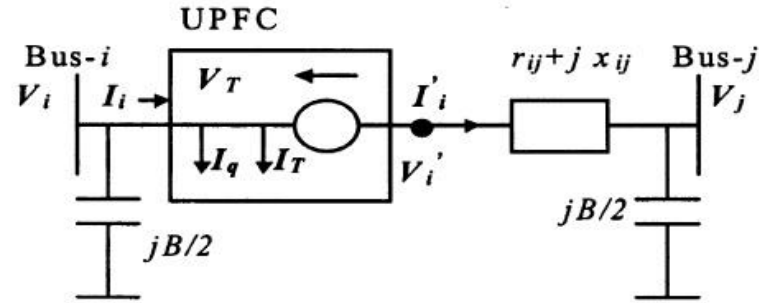

Fig.3. The UPFC Placed Between Bus-i And Bus-j

\section{PROBLEM FORMULATION}

Generating schedule can be obtained by solving the below objective function and with this schedule line flows can be found.

$$
\min \sum_{\mathrm{i}=1}^{\mathrm{N}_{\mathrm{G}}} \mathrm{C}_{\mathrm{G}_{\mathrm{i}}}\left(\mathrm{P}_{\mathrm{G}_{\mathrm{i}}}\right)-\sum_{\mathrm{i}=1}^{\mathrm{N}_{\mathrm{D}}} \mathrm{B}_{\mathrm{D}_{\mathrm{i}}}\left(\mathrm{P}_{\mathrm{D}_{\mathrm{i}}}\right)
$$

Subject to:

$$
P_{g_{i}}-P_{d_{i}}=\sum_{j=1}^{N_{B}}\left|V_{i}\right|\left|V_{j}\right|\left|Y_{i j}\right| \cos \left(\delta_{i}-\delta_{j}-\theta_{i j}\right)
$$




$$
\begin{aligned}
Q_{g_{i}}-Q_{d_{i}}=\sum_{j=1}^{N_{B}}\left|V_{i}\right|\left|V_{j}\right|\left|Y_{i j}\right| \sin \left(\delta_{i}-\delta_{j}-\theta_{i j}\right) \\
P_{g i, \text { min }} \leq P_{g i} \leq P_{g i, m a x} \\
Q_{g i, \text { min }} \leq Q_{g i} \leq Q_{g i, \text { max }} \\
P_{d i, \text { min }} \leq P_{d i} \leq P_{d i, \text { max }} \\
Q_{d i, \text { min }} \leq Q_{d i} \leq Q_{d i, \text { max }} \\
V_{i, \text { min }} \leq V_{i} \leq V_{i, \text { max }} \\
T_{i j} \geq 0
\end{aligned}
$$

Where,

$\mathrm{P}_{\mathrm{g}_{\mathrm{i}}} \quad=$ The real power generation at bus $\mathrm{i}$.

$\mathrm{Q}_{\mathrm{g}} \quad=$ The reactive power generation at bus $\mathrm{i}$.

$\mathrm{P}_{d_{\mathrm{i}}} \quad=$ The real power demand at bus $\mathrm{i}$.

$\mathrm{Q}_{d_{\mathrm{i}}} \quad=$ The reactive power demand at bus $\mathrm{i}$.

$\mathrm{V}_{\mathrm{i}} \quad=$ The voltage at bus $\mathrm{i}$.

$\delta_{\mathrm{i}} \quad=$ The power angle at bus $\mathrm{i}$.

$\mathrm{P}_{\mathrm{gi}, \mathrm{min}}=$ Minimum real power generation limit at bus $\mathrm{i}$.

$\mathrm{P}_{\text {gi,max }}=$ Maximum real power generation limit at bus $\mathrm{i}$.

$\mathrm{Q}_{\mathrm{gi}, \min }=$ Minimum reactive power generation limit at bus i.

$\mathrm{Q}_{\mathrm{gi}, \max }=$ Maximum reactive power generation limit at bus i.

$\mathrm{P}_{\mathrm{di}, \min }=$ Minimum real power demand limit at bus $\mathrm{i}$.

$\mathrm{P}_{\mathrm{di}, \max }=$ Maximum real power demand limit at bus $\mathrm{i}$.

$\mathrm{Q}_{\mathrm{di} \text {,min }}=$ Minimum reactive power demand limit at bus $\mathrm{i}$.

$\mathrm{Q}_{\mathrm{di} \text {,max }}=$ Maximum reactive power demand limit at bus i.

$\mathrm{C}_{\mathrm{G}_{\mathrm{i}}}\left(\mathrm{P}_{\mathrm{G}_{\mathrm{i}}}\right)=$ The cost function of $\mathrm{P}_{\mathrm{G}_{\mathrm{i}}}$ at bus $\mathrm{i}$.

$\mathrm{B}_{\mathrm{D}_{\mathrm{i}}}\left(\mathrm{P}_{\mathrm{D}_{\mathrm{i}}}\right)=$ The demand function of $\mathrm{P}_{d_{\mathrm{i}}}$ at bus $\mathrm{i}$.

$\mathrm{T}_{\mathrm{ij}} \quad=$ bilateral transaction between supplier at node $\mathrm{i}$ and consumer at node $\mathrm{j}$.

To solve the above optimization problem classical techniques like OPF suffers from the local optima and they need auxiliary information about the objective function Eqn.(7). By heuristic search methods global optima can be found. Among the heuristic search methods genetic algorithm (GA) is one of the good techniques.

\section{GENETIC ALGORITHM}

GA is general purpose optimization algorithm based on the mechanics of natural selection and genetics. They operate on string structures (chromosomes), typically a concatenated list of binary digits representing a coding of the control parameters (phenotype) of a given problem. Chromosomes themselves are composed of genes. GA is an attractive alternative to other optimization methods because of their robustness. There are four major differences between GA and conventional optimization algorithms [7], [8]. i). GA operates on the encoded string of the problem parameters rather than the actual parameters of the problem.

ii). GA uses a population of points rather than a single point in their search.

iii). GA does not require any prior knowledge, space limitations, or special properties of the function to be optimized, such as smoothness, convexity and existence of derivatives. They only require the evaluation of the so called Fitness Function (FF) to assign a quality value to every solution produced.

iv). GA use probabilistic transition rules, not deterministic rules. The FF evaluation and genetic evolution take part in an iterative procedure, which ends when a maximum number of generations are reached.

Assuming an initial random population produced and evaluated, genetic evaluation takes place by means of three basic genetic operators:

i). Parent selection

ii). Crossover

iii). Mutation

i). Parent selectionis a simple procedure where by two chromosomes are selected from the parent population based on their fitness value. Solutions with high fitness values have a high probability of controlling new offspring to the next generation. The selection rule used in this paper is a simple roulette-wheel selection.

ii). Crossoveris an extremely important operator for the GA. It is responsible for the structure recombination (information exchange between mating chromosomes) and the convergence speed of the GA and is usually applied with high probability $(0.6-0.9)$. The chromosomes of the two parents selected are combined to form new chromosomes that inherit segments or information stored in parent chromosomes. Until now, many crossover schemes, such as single point, multipoint, or uniform crossover have been proposed in the literature. Single point crossover has been used in this paper.

iii). Mutationis the operator responsible for the injection of new information. With a small probability, random bits of the offspring chromosomes flip from 0 to 1 and vice versa and give new characteristics that do not exist in the parent population. In this paper, the mutation operator is applied with a relatively small probability $(0.001-0.005)$ to every bit of the chromosome.

Operations of selection, crossover and mutation are repeated until the number of desired offsprings is created. The objective function is then calculated for every offsprings and the best individuals among the entire pool, comprising parents and their offsprings, are kept to constitute the new generation. The final result of the GA optimization is the best individual of the last iteration.

The termination criteria for GA will be any one of the following two conditions: 
i). The maximum number of generations is achieved.

ii). When the genotype of the population of individuals converges, the convergences of the genotype structure occur when all bit positions in all string are identical. In this case, crossover will have no further effect.

The steps to follow for GA are as shown in the flow chart as in fig.4.

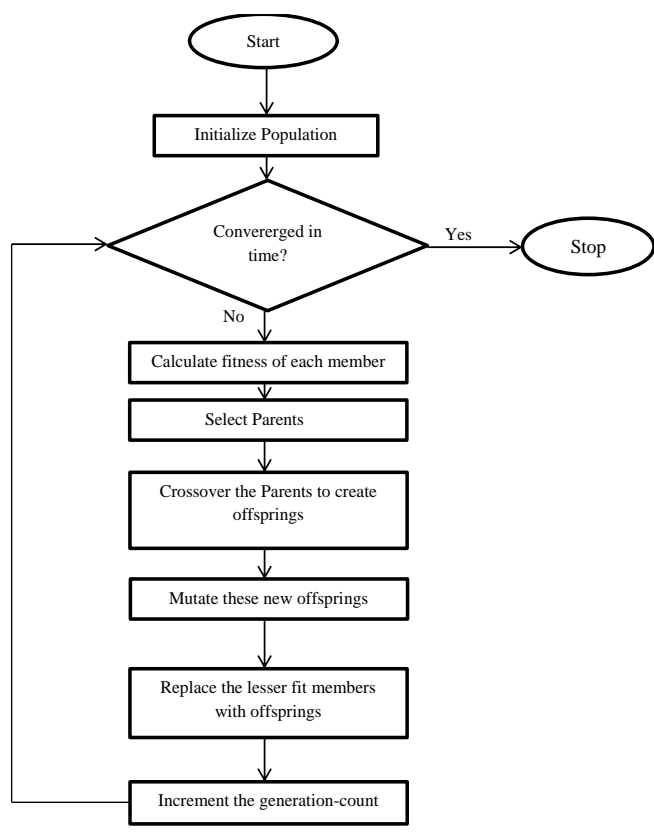

Fig.4: Flow chart of Genetic Algorithm

\section{OPTIMAL LOCATION OF SVC AND UPFC}

Even though FACTS devices offer many advantages, their installation cost is very high. So, ISO has to locate them at optimal locations. This task can be accomplished by considering many factors like cost, thermal limits of transmission lines, reactive power compensation, reduction of system losses, voltage limits and stability limits.

In this frame work optimization problem Eqn. (7) can be solved by using OPF technique while satisfying all the limitations Eqns. (8-14). This solution space is applied to GA which will give generator optimum schedule without transaction. This schedule results normal loading of transmission lines without congestion but when a bilateral transaction is done between seller and buyer it might cause transmission system to be congested. Let $P_{i j}$ be the power transaction requested from seller bus i to buyer bus $\mathrm{j}$, again optimum schedule is given by OPF with GA. By this solution we also get line flows which may be overloaded depends upon the transaction done by us. This solution also gives the optimal location of FACTS devices. The objective function is built in order to penalize the configuration of FACTS leading to overloaded transmission lines. In this work, only the technical benefits of the FACTS controllers, in terms of load ability, are taken into account [11]

Copyright to IJIREEICE

\section{RESULTS AND DISCUSSION}

The proposed model has been implemented and tested on IEEE 30-bus test system [12]. Various parameters used in solving OPF using GA are given in Table 1. The objective function is solved by GA and optimum generating schedule before transaction is shown in Table 2 and optimal social welfare is Rs.1, 82, 919.

Table 1: GA Parameters

\begin{tabular}{|c|c|}
\hline Population Size & 200 \\
\hline Mutation Rate & 0.001 \\
\hline Crossover Rate & 0.8 \\
\hline Maximum Iterations & 50 \\
\hline Crossover operator & Single Point \\
\hline Selector Operator & Roulette Wheel \\
\hline
\end{tabular}

Table 2: Optimal Generation Schedule without Transaction

\begin{tabular}{|c|c|}
\hline Generator No: & Pg (MW) \\
\hline Generator 1 & 35.77 \\
\hline Generator 2 & 49.74 \\
\hline Generator 3 & 17.37 \\
\hline Generator 4 & 21.78 \\
\hline Generator 5 & 18.90 \\
\hline Generator 6 & 49.68 \\
\hline
\end{tabular}

The problem optimization is shown in Fig. 5, the line power flows are calculated and line loading without transaction is shown in the Fig. 6.

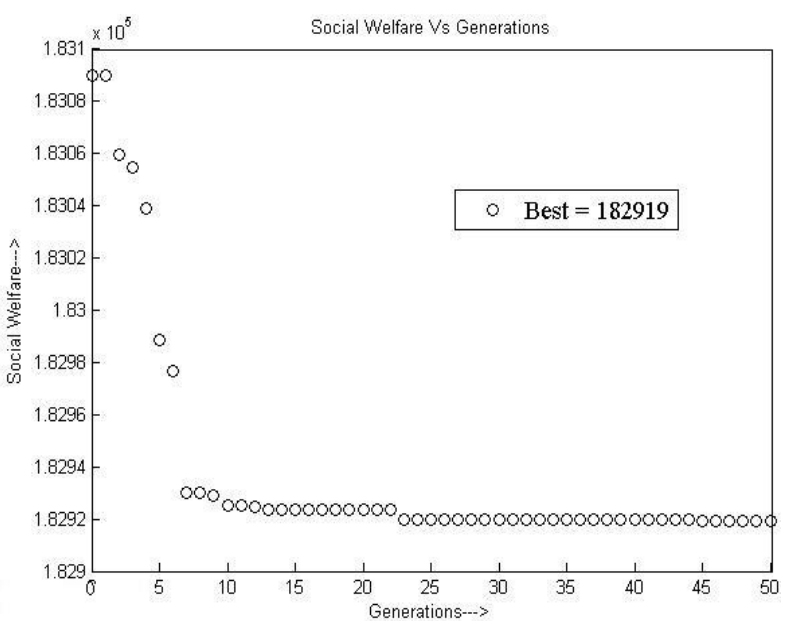

Fig. 5: Social welfare vs. generations without transaction 


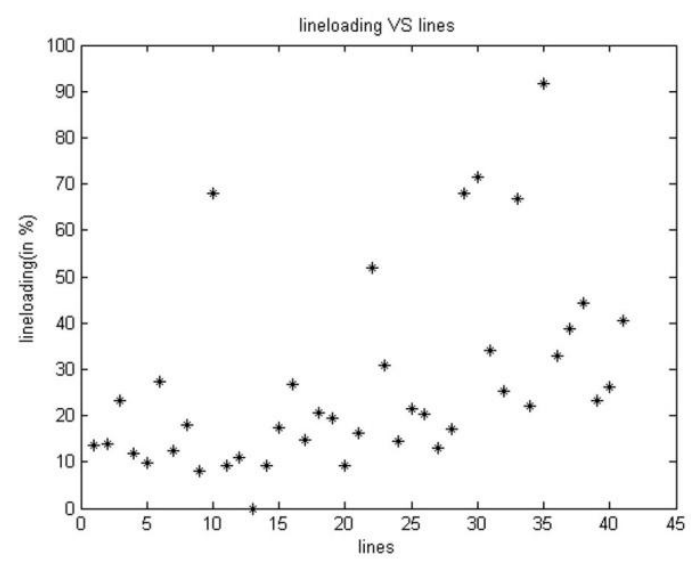

Fig. 6: Line loading without transaction

The problem optimization is shown in Fig. 7, the line power flows are calculated and line loading with transaction is shown in the Fig. 8. Optimum generating schedule after transaction is shown in Table.3 and optimal social welfare is Rs.2, 16, 261.

Here, in Fig. 8, observe that the line 35 is congested. To relieve congestion, best location of FACTS devices captured from Fig.8. The congested lines as well as the neighbourhood lines that are linked to the congested lines found by using OPF with GA. By installing SVC at optimal location, observe that the percentage line loading in line 35 is reduced in Fig. 9 as compared in Fig. 8. By installing UPFC at optimal location, Once again line loadings are still gets reduced in line 35 as shown in Fig. 10 as compared with earlier two cases.

Table 3: Optimal Generation Schedule with Transaction

\begin{tabular}{|c|c|}
\hline Generator No: & Pg (MW) \\
\hline Generator 1 & 42.28 \\
\hline Generator 2 & 57.36 \\
\hline Generator 3 & 23.48 \\
\hline Generator 4 & 25.47 \\
\hline Generator 5 & 22.94 \\
\hline Generator 6 & 55.00 \\
\hline
\end{tabular}

By locating SVC in the line 35, the percentage line loading has reduced from $109.43 \%$ to $89.94 \%$ as shown in Fig.9. Same in the case of installing UPFC in the line 35, the percentage line loading has reduced from $109.43 \%$ to $89.48 \%$.

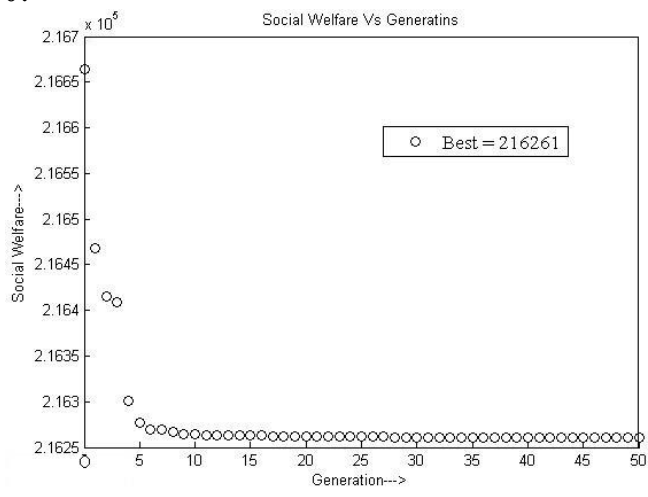

Fig. 7: Social welfare vs. generations with transaction Copyright to IJIREEICE

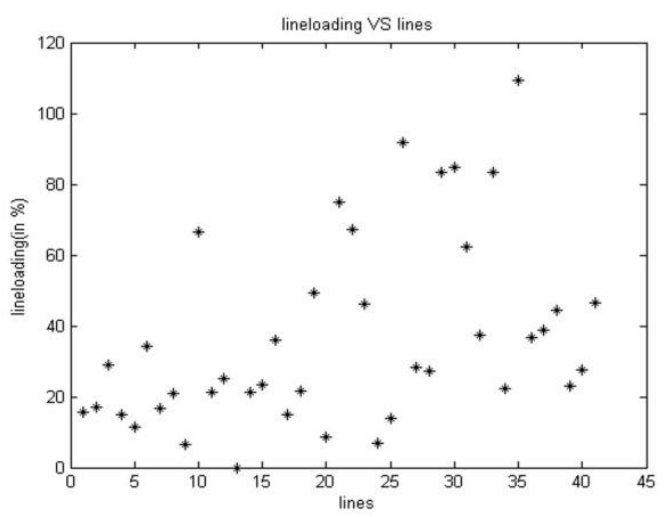

Fig. 8: Line loading with transaction

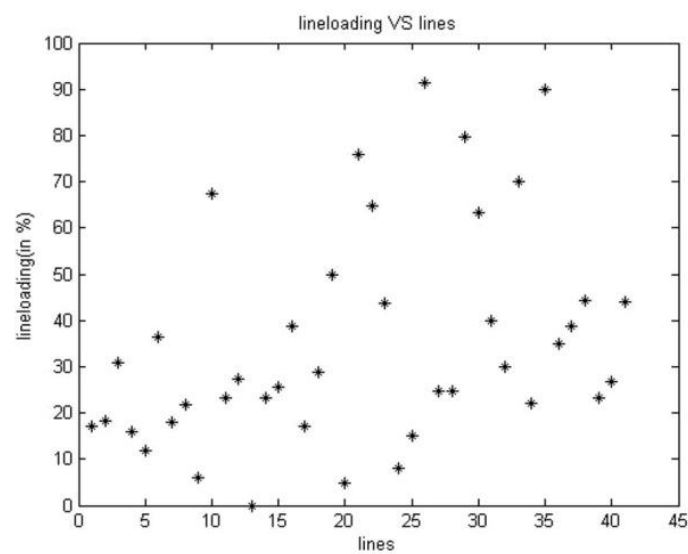

Fig. 9: Line loading installing SVC with a transaction

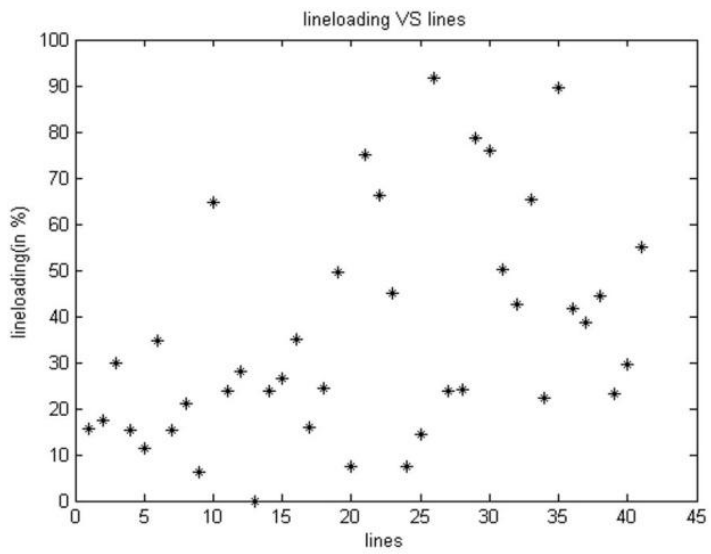

Fig. 10: Line loading installing UPFC with a transaction

\section{CONCLUSION}

It is confirmed that congestion in the transmission line is relieved by placing FACTS devices i.e., by using SVC and UPFC. It is proved that line loading reduction in case of UPFC is more as compared with SVC.

\section{REFERENCES}

[1] Deependra Singh and K. S. Verma, "GA-based Congestion Management in Deregulated Power System using FACTS Devices ", IEEE Trans on power system, 2012.

[2] Keshi Reddy Saidi Reddy, N. P. Padhy and R. N. Patel, "Congestion management in deregulated power system using FACTS devices", IEEE Trans on power system, June 2006. 
[3] R. S. Fang and A. K. David, "Optimal Dispatch under transmission contracts," IEEE Transactions on Power Systems", vol. 14, No.2, pp.732- 737, May 1999.

[4] Harry Singh, Shan You, and Alex Papalexopalos, "Transmission congestion management in competitive electricity market," IEEETransactions on Power Systems, vol. 13, No. 2, pp.672-680, May 1998.

[5] S. N. Singh, and A. K. David, "Congestion Management by Optimizing FACTS Device Location", International Conference on Electric Utility Deregulation and Restructuring and Power Technologies, 2000.

[6] S. N. Singh, and A. K. David, "Optimal location of FACTS devices for congestion management", Electric Power Systems Research, vol. 58, No. 2, pp. 71-79, July 2001.

[7] T. S. Chung, and Y. Z. Li, "A hybrid GA approach for OPF with consideration of FACTS devices", IEEE Power Engineering Review, pp. 47-50, February 2001.

[8] H. C. Leung and T. S. Chung, "Optimal power flow with a versatile FACTS controller by genetic algorithm approach", in Proc. Powerengineering society winter meeting, 2000, vol.4, pp. 28062811, Jan. 2000.

[9] N.G. Hingorani and L.Gyugyi, "Understanding FACTS", the Institution of Electrical and Electronics Engineers, 1998.

[10] K.S. Verma, S.N. Singh, H.O. Gupta, "Location of unified power flow controller for congestion management"Electric Power Systems Research 58 (2001).

[11] StéphaneGerbex, RachidCherkaoui, and Alain J. Germond, Member, IEEE "Optimal Location of Multi-Type FACTS Devices in a Power System by Means of Genetic Algorithms", IEEE transactions on power systems, vol. 16, no. 3, august 2001.

[12] http://www.ee.washington.edu.

\section{BIOGRAPHIES}

S. Vinod Kumar, pursuing his M.Tech in Electrical Power Systems Engineering from JNTUA college of Engineering, Pulivendula-516390, A.P, India.

J Sreenivasulu, working as Asst. Professor at the EEE Department of JNTUACEP, Pulivendula, A.P, India.

K. Vimala Kumar, working as Asst. Professor at the EEE Department of JNTUACEP, Pulivendula, A.P, India. 